\title{
Abnormal uterine bleeding: A study of its clinical spectrum and incidence of histopathological patterns of endometrium as a function of age with parity
}

\author{
Nidhi Golecha',*, Varsha Porwal ${ }^{2}$ \\ ${ }^{1}$ Senior Specialist, ${ }^{2}$ Senior Demonstrator, ${ }^{1}$ Dept. of Obstetrics and Gynecology, ${ }^{2}$ Dept. of Anatomy, Jhalawar Hospital \& Medical \\ College, Jhalawar, Rajasthan, India \\ *Corresponding Author: \\ Email: nidhijwr24@gmail.com
}

Received: $12^{\text {th }}$ April, 2018

Accepted: $8^{\text {th }}$ May, 2018

\begin{abstract}
Introduction: Abnormal uterine bleeding (AUB) is a common complaint affecting majority of pre and postmenopausal women. Endometirum is a dynamic tissue and is affected by a wide range of histopathological lesions. The causes of AUB is a function of age.

Aim and Objective: to study the histopathological pattern in cases of AUB in reference age, parity and bleeding pattern. Patients were categorized into reproductive ( $<40$ years), perimenopausal (40-50 years) and postmenopausal ( $>50$ years).

Materials and Methods: A total of three hundred patients presenting with AUB are included in this study.

Observation and Results: In this study patient ranged from 20 to 70 years and the mean age of the cohort was $43.46 \pm 8.07$. Major parity category noted in the cohort was para-2 in 89 patients $(29.67 \%)$. Major bleeding pattern observed in the cohort was menorrhagia (32.33\%); followed by metrorrhagia (19.67\%), menometrorrhagia (16.33\%), postmenopausal bleeding (12.67\%), polymenorrhoea $(9.67 \%)$, polymenorrhagia $(5 \%)$ and continuous bleeding $(1 \%)$. Histopathological pattern observed in AUB patients was proliferative phase endometrium (31.33\%), secretory phase endometrium (21.67\%), menstrual endometrium $(1.33 \%)$. atrophic endometrium (6\%), disordered proliferation $(3.33 \%)$, mixed pattern (1\%), polyp (10.67\%), metaplasia (9.67\%), hyperplasia $(8.67 \%)$, endometritis $(2.67 \%)$, adenocarcinoma $(1.67 \%)$ and insufficient $(2 \%)$.

Conclusion: The causes of AUB are function of age; perimenopausal age group is the most common affected. Dilatation \& Curettage is cost effective, useful procedure but organic lesions such as leiomyoma and adenomyosis can be missed. AUB is a common disorder affecting females and is a challenge to the treating gynaecologist.
\end{abstract}

Keywords: Endometrium, Premenopausal, Postmenopausal, Hyperplasia, Polyp.

\section{Introduction}

Abnormal uterine bleeding (AUB) is considered one of the most common and challenging problems presenting to the gynecologist. Its prevalence is seen in majority of pre- and postmenopausal women visiting gynecologist. ${ }^{1,2}$ AUB is a deviation from normal menstruation or in other words unscheduled or unexpected uterine bleeding. It is categorized in different ways based on underlying cause and morphology. Endometrium is influenced by wide range of organic, abnormal histological alterations, inflammatory/infectious causes and functional disorders thereby posing a challenge to the physician. The underlying causes of AUB are a function of age group.

For adolescent women AUB is mostly transient due to disorders of the hypothalamic-pituitary axis; anovulatory bleeding is the common cause if severe bleeding is present. For women in the third and fourth decades, a range of organic lesions occur and other causes of bleeding which must be excluded are contraceptives, pregnancy, including ectopic gestations. The fifth decade witnesses the approach of menopause when AUB heralds the anovulatory cycle. In the six and seventh decades particularly the possibility of a neoplastic process is investigated where hormonal replacement therapy was excluded.
The pathophysiology of endometrial breakdown in AUB is mediated by inflammatory (endometritis) or vascular (fragility) phenomena in presence of organic lesions; and impaired vasoconstriction and fibrinolysis in the absence of a morphologic abnormality. ${ }^{3}$

Endometrial biopsy and curettage remain the primary diagnostic procedure to investigate potential endometrial pathology. ${ }^{4}$ Dilatation and curettage provides a safe, quick and cost-effective diagnostic tool that provides useful information regarding endometrial status, infections and/or organic lesions. ${ }^{5,6}$

The objective of this study is to determine the types and frequencies of endometrial histopathological pattern in cases of AUB in reference age, parity and bleeding pattern. This may be of helpful to treating gynecologists in planning the diagnosing, therapeutic, or operative strategies.

\section{Materials and Methods}

This prospective study was done on three hundred patients, who presented with abnormal uterine bleeding. This study includes patients who have given consent.

Exclusion Criteria: Patients with IUCD in situ, Pregnancy; diagnosed with systemic diseases; liver or renal diseases; genital tuberculosis; known malignancy lesion other than endometrial origin; Endocrine disorders; Coagulation disorders; on medications like 
steroids, anticoagulants and hormonal replacement therapy.

Data was collected using semi structured Questionnaire. The diagnosis in 300 AUB patients was obtained post-curettage/ hysterectomy in 170 and 130 patients, respectively patients were categorized into reproductive ( $<40$ years), perimenopausal (40-50 years) and postmenopausal (>50 years) age groups. Data was statistically analyzed wherever applicable.

\section{Endometrial histopathological diagnosis was} classified as follows:

1. Normal physiological changes: Proliferative phase endometrium (PP), Secretory phase endometrium (SP) and Menstrual phase endometrium.

2. Dysfunctional changes: Disordered proliferation, mixed pattern endometrium and Atrophic endometrium.
3. Organic lesions: Chronic endometritis, endometrial polyp, endometrial hyperplasia without atypia, atypical hyperplasia, metaplasia and malignancy e.g. adenocarcinoma.

4. Insufficient for evaluation.

\section{Observations and Results}

Among the three hundred AUB patients included in this study majority were in $4^{\text {th }}$ and $3^{\text {rd }}$ decade with $68.33 \%$ and $32 \%$ respectively. Distribution of patients in three age groups is shown in table 1. In this study patient ranged from 20 to 70 years and the mean age of the cohort was $43.46 \pm 8.07$. Major parity category noted in the cohort was para-2 in 89 patients $(29.67 \%)$.

Table 1: Demographics of AUB cases in three age groups

\begin{tabular}{|c|c|c|c|}
\hline & $\begin{array}{c}\text { Reproductive } \\
\text { (<40 years })\end{array}$ & $\begin{array}{c}\text { Perimenopausal } \\
(40-50 \text { years })\end{array}$ & $\begin{array}{c}\text { Postmenopausal } \\
(>50 \text { years })\end{array}$ \\
\hline Number & 65 & 205 & 30 \\
\hline$\%$ & $21.67 \%$ & $68.33 \%$ & $10 \%$ \\
\hline Mean age \pm SD & $32.49 \pm 4.02$ & $44.73 \pm 3.66$ & $58.57 \pm 4.99$ \\
\hline \multicolumn{4}{|l|}{ Parity } \\
\hline Nullipara & 6 & 3 & 0 \\
\hline Para 1 & 7 & 12 & 0 \\
\hline Para 2 & 25 & 59 & 5 \\
\hline Para 3 & 19 & 54 & 6 \\
\hline Para 4 & 5 & 46 & 8 \\
\hline Grand multipara & 3 & 31 & 11 \\
\hline Total & 65 & 205 & 30 \\
\hline Major bleeding pattern (n,\%) & $\begin{array}{l}\text { Menorrhagia } \\
(38,58.46 \%) \\
\end{array}$ & $\begin{array}{l}\text { Menorrhagia } \\
(58,28.29 \%) \\
\end{array}$ & $\begin{array}{c}\text { Postmenopausal bleeding } \\
(27,90 \%)\end{array}$ \\
\hline $\begin{array}{l}\text { Major normal histology } \\
\text { diagnosis }(\mathrm{n}, \%)\end{array}$ & $\begin{array}{l}\text { Proliferative phase } \\
\quad(26,40 \%)\end{array}$ & $\begin{array}{c}\text { Proliferative phase } \\
(66,32.2 \%)\end{array}$ & $\begin{array}{c}\text { Secretory phase } \\
(4,13.3 \%)\end{array}$ \\
\hline $\begin{array}{l}\text { Major dysfunctional } \\
\text { histopathological diagnosis } \\
(\mathrm{n}, \%)\end{array}$ & $\begin{array}{l}\text { Disordered proliferation } \\
\qquad(3,4.62 \%)\end{array}$ & $\begin{array}{l}\text { Atrophic endometrium } \\
\qquad(10,4.88 \%)\end{array}$ & $\begin{array}{l}\text { Atrophic endometrium } \\
\qquad(8,26.67 \%)\end{array}$ \\
\hline $\begin{array}{l}\text { Major organic histopathological } \\
\text { diagnosis }(\mathrm{n}, \%)\end{array}$ & $\begin{array}{l}\text { Metaplasia } \\
(7,10.77 \%)\end{array}$ & $\begin{array}{c}\text { Polyp } \\
(24,11.71 \%)\end{array}$ & $\begin{array}{c}\text { Adenocarcinoma/ Atypical } \\
\text { hyperplasia } \\
(4,13.33 \% \text { each })\end{array}$ \\
\hline
\end{tabular}

Major bleeding pattern observed in the cohort was menorrhagia in 97 (32.33\%); followed by metrorrhagia in 59 (19.67\%), menometrorrhagia in $49(16.33 \%)$, postmenopausal bleeding in 38 (12.67\%), polymenorrhoea in 29 $(9.67 \%)$, polymenorrhagia in $15(5 \%)$ and continuous bleeding in 3 patients $(1 \%)$.

Table 2: Type of endometrial pattern seen in three age groups of AUB cases

\begin{tabular}{|c|c|c|c|c|c|c|c|c|c|}
\hline \multirow[t]{2}{*}{ S. No } & \multirow[t]{2}{*}{ Endometrial Histological status } & \multicolumn{2}{|c|}{$\begin{array}{c}\text { Reproductive }(<40 \\
\text { years) }\end{array}$} & \multicolumn{2}{|c|}{$\begin{array}{c}\text { Perimenopausal } \\
(\mathbf{4 0 - 5 0} \text { years })\end{array}$} & \multicolumn{2}{|c|}{$\begin{array}{l}\text { Postmenopaus } \\
\text { al (>50 years) }\end{array}$} & \multicolumn{2}{|c|}{ Total } \\
\hline & & n & $\%$ & $\mathbf{n}$ & $\%$ & n & $\%$ & $\mathbf{n}$ & $\%$ \\
\hline 1. & Adenocarcinoma & 1 & 0.33 & - & - & 4 & 1.33 & 5 & 1.67 \\
\hline 2. & Atrophic Endometrium & - & - & 10 & 3.33 & 8 & 2.67 & 18 & 6 \\
\hline 3. & Disordered Proliferation & 3 & 1.00 & 7 & 2.33 & - & - & 10 & 3.33 \\
\hline 4. & Endometritis & 2 & 0.67 & 5 & 1.67 & 1 & 0.33 & 8 & 2.67 \\
\hline 5. & Hyperplasia without Atypia & 4 & 1.33 & 13 & 4.33 & 2 & 0.67 & 19 & 6.33 \\
\hline 6. & Atypial Hyperplasia / EIN & - & - & 3 & 1.00 & 4 & 1.33 & 7 & 2.33 \\
\hline 7. & Insufficient & 1 & 0.33 & 4 & 1.33 & 1 & 0.33 & 6 & 2 \\
\hline 8. & Menstrual Endometrium & - & - & 4 & 1.33 & - & - & 4 & 1.33 \\
\hline 9. & Metaplasia & 7 & 2.33 & 21 & 7.00 & 1 & 0.33 & 29 & 9.67 \\
\hline
\end{tabular}




\begin{tabular}{|l|c|c|c|c|c|c|c|c|c|}
\hline 10. & Polyp & 5 & 1.67 & 24 & 8.00 & 3 & 1.00 & 32 & 10.67 \\
\hline 11. & Proliferative endometrium & 26 & 8.67 & 66 & 22.00 & 2 & 0.67 & 94 & 31.33 \\
\hline 12. & Secretory endometrium & 14 & 4.67 & 47 & 15.67 & 4 & 1.33 & 65 & 21.67 \\
\hline 13. & Mixed pattern & 2 & 0.67 & 1 & 0.33 & - & - & 3 & 1 \\
\hline & Total & 65 & 21.67 & 205 & 68.33 & 30 & 10.00 & 300 & 100 \\
\hline
\end{tabular}

Table 3: Shows relation between type of endometrial histopathology and the type of bleeding pattern

\begin{tabular}{|c|c|c|c|c|c|c|c|c|c|}
\hline 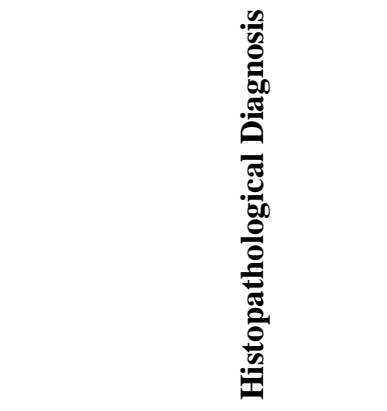 & 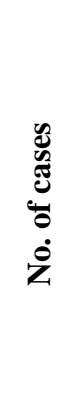 & 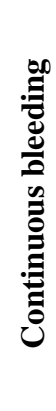 & 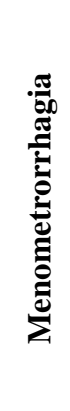 & 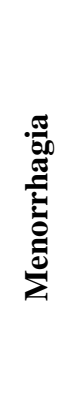 & & 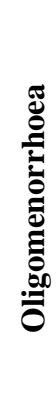 & 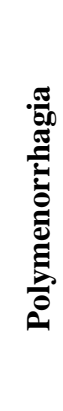 & 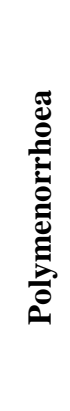 & 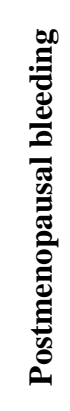 \\
\hline Adenocarcinoma & 5 & - & & & 2 & & & & 3 \\
\hline Atrophic Endometrium & 17 & & & 3 & 3 & 4 & - & - & 8 \\
\hline Disordered Proliferation & 10 & 1 & & 5 & 3 & - & - & 1 & - \\
\hline Endometritis & 7 & - & 3 & - & - & - & 1 & 2 & 2 \\
\hline Hyperplasia without Atypia & 18 & - & 4 & 7 & 3 & - & 1 & 2 & 2 \\
\hline Atypial Hyperplasia & 7 & - & 1 & - & 2 & - & - & 1 & 3 \\
\hline Insufficient & 6 & - & - & 2 & 2 & - & 1 & - & 1 \\
\hline Menstrual Endometrium & 3 & - & - & 3 & 1 & - & - & - & - \\
\hline Metaplasia & 29 & 1 & 3 & 8 & 9 & 4 & - & 3 & 1 \\
\hline Polyp & 32 & 1 & 8 & 9 & 2 & 2 & 3 & 1 & 6 \\
\hline Proliferative Phase & 93 & - & 15 & 35 & 23 & - & 6 & 10 & 5 \\
\hline Secretory Phase & 65 & - & 14 & 24 & 8 & - & 3 & 9 & 7 \\
\hline Mixed endometrium & 3 & - & 1 & 1 & 1 & - & - & - & - \\
\hline Total & 300 & 3 & 49 & 97 & 59 & 10 & 15 & 29 & 38 \\
\hline
\end{tabular}

\section{Discussion}

Endometrium is an evidently dynamic, hormonally sensitive and responsive tissue which constantly undergoes changes during the reproductive life.
Age Incidence: In this study we witnessed highest incidence of AUB cases in perimenopausal followed by reproductive and postmenopausal age group; $50.33 \%$, $39.67 \%$ and $10 \%$ respectively. Similar results were reported by S. Vaidya et al. ${ }^{7}$, it was $46.15 \%, 37.97 \%$ and $15.88 \%$ respectively.

Table 4: Shows comparison of parity in AUB cases with other studies

\begin{tabular}{|c|c|c|c|c|c|c|c|c|c|c|c|}
\hline \multirow{2}{*}{ Parity } & \multicolumn{2}{|c|}{ Sadia khan ${ }^{8}$} & \multicolumn{2}{|c|}{ 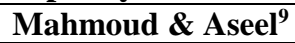 } & \multicolumn{2}{|c|}{ Smita \& Manik ${ }^{10}$} & \multicolumn{2}{|c|}{ Jagadale Kunda ${ }^{11}$} & \multicolumn{3}{|c|}{ Present study } \\
\hline & Total & $\%$ & Total & $\%$ & Total & $\%$ & Total & $\%$ & Total & $\%$ & $\%$ \\
\hline Nullipara & 27 & 5.4 & 38 & 7.3 & 18 & 8.57 & 8 & 8 & 9 & 3 & 3 \\
\hline Para 1 & 07 & 181 & 00 & 188 & 25 & 11.9 & 34 & 34 & 19 & 6.33 & 36 \\
\hline Para 2 & 92 & 10.4 & (7) & 10.0 & 128 & 6005 & - & & 89 & 29.67 & 50 \\
\hline Para 3 & 178 & 356 & 186 & 354 & 120 & ני. & - & 58 & 79 & 26.33 & 46 \\
\hline Para 4 & 170 & 55.0 & 100 & 35.4 & 30 & 1857 & - & Jo & 59 & 19.67 & 40 \\
\hline Para $\geq 5$ & 203 & 40.6 & 202 & 38.5 & 39 & 10.01 & - & & 45 & 15 & 15 \\
\hline Total & 500 & 100 & 525 & 100 & 210 & 100 & 100 & 100 & 300 & 100 & 100 \\
\hline
\end{tabular}

Parity: In the present study, the highest incidence of AUB was seen in multiparous women this is in similarity with other authors as shown in table 4 as well as by most other investigators. ${ }^{10,12}$ The lowest incidence of AUB was seen in nulliparous women in the present study (3\%) which is in close similarity with Radha $\mathrm{N}^{12}$ $(4 \%)$ and Sadia $\mathrm{K}^{8}(5.4 \%)$.
Bleeding Pattern: Menorrhagia was the most common type of bleeding noted in the present study and by other authors. Next common bleeding pattern observed was metrorrhagia, this is similar to Zeeba, ${ }^{13}$ Preeti. ${ }^{14}$ Therefore together menorrhagia and metrorrhagia constitutes the majority of bleeding pattern type and this is in concordance with most other studies (Table 5). 
Table 5: Comparison of bleeding pattern with other studies (in\%)

\begin{tabular}{|c|c|c|c|c|c|c|c|c|c|}
\hline$\frac{n}{\stackrel{n}{E}}$ & 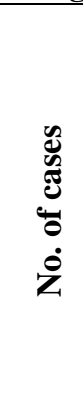 & 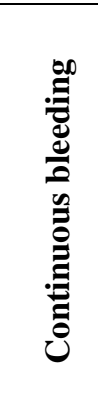 & 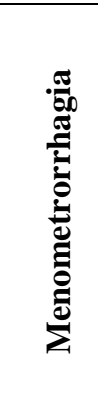 & 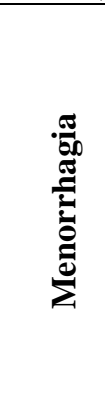 & 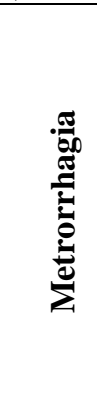 & 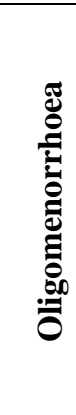 & 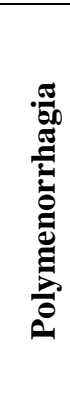 & 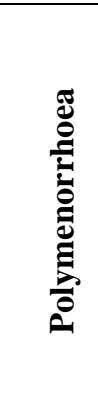 & 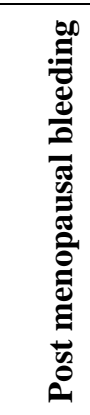 \\
\hline Moghal N ${ }^{15}$ & 458 & - & - & 41 & 48 & - & - & 1.74 & 6.1 \\
\hline Zeeba $\mathrm{S}^{13}$ & 462 & 14 & 5 & 41 & 18 & 9 & 4 & 6 & 3 \\
\hline Preeti et $\mathrm{al}^{16}$ & 212 & 3.77 & - & 38.68 & 11.32 & - & - & 12.74 & 24.52 \\
\hline Mahmoud \& Aseel ${ }^{9}$ & 525 & 8.8 & 18.9 & 42.7 & 4.2 & - & 7.6 & 1.5 & 16.3 \\
\hline Jagadale $\mathrm{K}^{11}$ & 100 & - & 1 & 88 & 3 & - & - & - & 8 \\
\hline Sheetal et al ${ }^{17}$ & 100 & 9 & 1 & 25 & 5 & 17 & 13 & 6 & 7 \\
\hline Present study & 300 & 1 & 16.33 & 32.33 & 19.67 & 3.33 & 5 & 9.67 & 12.67 \\
\hline
\end{tabular}

Histopathological Diagnosis: In the present study, the most common entity was normal cyclic endometrium: PP (31.33\%), SP (21.67\%) and menstrual (1.33\%), total amounting to $54.33 \%$. Where PP and SP together were most prevalent entity and this is in concordance with most authors. . $^{18,19,7,20,21,13,11}$ Menstrual endometrium $(1.33 \%)$ is in similarity with $1.28 \%,{ }^{22} 1.1 \%{ }^{4}$

Endometrial Polyp $(\mathrm{n}=32, \quad 10.67 \%)$ was the commonest organic histopathological lesion observed. Its occurrence was similar to mencaglia ${ }^{2}$ but higher than other studies by $5 \%,{ }^{17} 2.46 \%,{ }^{23} 2.63 \% .{ }^{19}$ Though in this study majority $(62.5 \%)$ of polyp cases were seen in $4^{\text {th }}$ decade and this is in concordance with $54.5 \%,{ }^{13} 40 \%{ }^{19}$ and $39.1 \% .^{24}$ Polyps increase in frequency with age; late menopause, hypertension and obesity are associated with polyps.

Metaplasia was seen in ( $\mathrm{n}=29,67 \%)$ cases; similar to reported by Talat $\operatorname{Mirza}^{25}(\mathrm{n}=25,6 \%)$. Among the 29 cases of metaplasia, squamous metaplasia was seen in 26 cases and tubal metaplasia was seen 3 cases respectively.

Atrophic Endometrium ( $\mathrm{n}=18,6 \%)$ was similar to $7 \%,{ }^{25} 6.72 \%,{ }^{26} 7.38 \%{ }^{23}$ and $5.12 \%{ }^{22}$ near comparable results are $4.71 \%,{ }^{7} 3.5 \%{ }^{21} \& 2.44 \% .{ }^{24}$ The difference is due to different composition of cohort. Atrophic endometrium was seen predominantly in postmenopausal age group, the reason is that decreased estrogenic stimulation leads to thin atrophic endometrium making it susceptible to minor injury and may cause bleeding even in absence of any identifiable lesion. $^{23}$

Hyperplasia was $(n=26,8.67 \%)$ and comparable to other authors $9.1 \%,{ }^{18} 10.92 \%^{7} ; 6.11 \%^{24}$ and $12.6 \%{ }^{8}$ but it is much lower than $41.9 \%,{ }^{10} 30.3 \%,{ }^{4} 25 \%{ }^{22}$ and $25.5 \% .{ }^{21}$ In this study $61.5 \%$ of hyperplasia was noted in perimenopausal age group. Similar results were $57.1 \%,{ }^{19} 64.8 \%{ }^{13}$ and $68 \%,{ }^{24}$ Wahda Moohamed ${ }^{4}$ found statistical significant correlation between hyperplasia and perimenopausal age group $(\mathrm{p}<0.05)$. Unopposed estrogen level, genetic factor, obesity and medication like tamoxifen act as risk factors in females to develop endometrial hyperplasias. ${ }^{27}$ Therefore endometrial histopathological evaluation cannot be underestimated in perimenopausal women.

Disordered Proliferation was $(\mathrm{n}=10,3.33 \%)$ similar to $3 \%,{ }^{21} 4.8 \%{ }^{13}$ where other reported $6.56 \%,{ }^{23} 15.9 \%,{ }^{26}$ $13 \%^{25} ; 13.4 \%$; and $20.54 \% .{ }^{24}$ Anovulatory cycles play role in development of disordered proliferation, and although risk of malignancy is less than $2 \%$ but it should be thoroughly evaluated. ${ }^{28}$ Chronic endometritis can be caused by IUCD, PID, abortion or mucopurulent cervicitis. It was noted in $(\mathrm{n}=8,2.67 \%)$, similar data is $2.6 \%,{ }^{19} 2.74 \%,{ }^{24} 3.23 \%$. $^{7}$

Endometrial Carcinoma was $(\mathrm{n}=5,1.67 \%)$ and it is comparable with most authors $1.49 \%,{ }^{29} 1.06 \%,{ }^{30} 1 \%{ }^{21}$; $2 \%,{ }^{25} 2.38 \%{ }^{10}$ and $2.48 \% .{ }^{7}$ Among these 5 patients only one was 40 years and rest four patients were above 55 years. Other authors also reported higher incidence of carcinoma above 50 years of age.

Mixed Pattern was $(n=3,1 \%)$ where other reported $1.89 \%,{ }^{16} 3 \%,{ }^{21} 3.85 \%$ and $8.3 \% .{ }^{4}$ Mixed endometrium includes pill endometrium therefore its incidence will depend on the type of patients included in the study.

Among the 130 hysterectomy specimen included, 26 specimens revealed other pathologies affecting the uterine wall in addition to endometrial lesions detected in these cases. These include adenomyosis in 10 cases ( $7.81 \%)$, leiomyoma in 16 cases $(12.5 \%)$.

\section{Conclusion}

The causes of AUB are function of age; perimenopausal age group is the most common affected; and there is wide range of histopathological and functional reasons. Most common entities are in clinical pattern (Menorrhagia); normal histological finding (Proliferative phase); dysfunctional change 
(Atrophic endometrim) and organic Endometrial lesion (polyp). Dilatation \& curettage is cost effective, useful procedure but organic lesions such as leiomyoma and adenomyosis can be missed. AUB is a common disorder affecting females and is a challenge to the treating gynaecologist.

\section{References}

1. Wieser F, Tempfer C, Kurz C, Nagele F. Hysteroscopy in 2001: a comprehensive review. Acta Obstet Gynecol Scand. 2001;80(9):773-783.

2. Mencaglia L, Perino A, Hamou J. Hysteroscopy in perimenopausal and postmenopausal women with abnormal uterine bleeding. J Reprod Med. 1987;32(8):577-582.

3. Ferenczy A. Pathophysiology of endometrial bleeding. Maturitas. 2003;45(1):1-14.

4. Al-Neaimy WMT, Ahmed MT, Al-Jawadi SI. Histopathological Interpretation of Abnormal Uterine Bleeding After the Age of 40 Year. iraqi Postgrad Med J. 2010;9(3):274-282.

5. Sarwar A, Ul Haque A. Types and Frequencies of Pathologies in Endometrial Curettings of Abnormal Uterine Bleeding. Int J Pathol. 2005;3(2):65-70.

6. Mesci-Haftaci S, Ankarali H, Yavuzcan A, Caglar M. Endometrial Curettage in Abnormal Uterine Bleeding and Efficacy of Progestins for Control in Cases of Hyperplasia. Asian Pacific J Cancer Prev. 2014;15(8):3737-3740.

7. Vaidya S, Lakhey M, Vaidya SA, et al. Histopathological pattern of abnormal uterine bleeding in endometrial biopsies. 2013;15(1):74-77.

8. Khan S, Hameed S, Umber A. Histopathological Pattern of Endometrium on Diagnostic D \& C in Patients with Abnormal Uterine Bleeding. ANNALS. 2011;17(2 APRJUN):166-170.

9. Mahmoud MM, Rifat aseel ghazi. Endometrial Histopathological Changes in Women with Abnormal Uterine Bleeding in Kirkuk City, a Clinicopathological Study. Med J Babylon. 2013;10(3):567-582.

10. Patne SS, Sirpurkar MS. Validation of endometrial curettage in abnormal uterine bleeding in a teaching institute of central India: A prospective study. Int J Med Res Heal Sci. 2013;2(3):491-495. doi:10.5958/j.23195886.2.3.085.

11. Kunda J, Sharma A. Histopathlogical study of endometrium in abnormal uterine bleeding in refernce to different age groups, parity and clinical symptomatology. Int J Clin Biomed Res. 2015;1(2):90-95.

12. Nair R, M M. Clinical profile of patients with pulmonary embolism at a tertiary care hospital. Indian Heart J. 2013;65(December):S89.

13. Jairajpuri ZS, Rana S, Jetley S. Atypical uterine bleedingHistopathological audit of endometrium A study of 638 cases. Al Ameen J Med Sci. 2013;6(1):21-28.

14. Singh P, Jaiswal VK, Garg P. Endometrial patterns in abnormal uterine bleeding. 2016;7(5):244-250. doi:10.7439/ijbr.

15. Moghal N. Diagnostic value of endometrial curettage in abnormal uterine bleeding--a histopathological study. $J$ Pak Med Assoc. 1997;47(12):295-299.

16. Singh P, Jaiswal VK, Garg P. Endometrial patterns in abnormal uterine bleeding. Int J Biomed Res. 2016;7(5):244-250. doi:10.7439/ijbr.

17. Patil SG, Bhute SB, Inamdar SA, Acharya NS, Shrivastava DS. Role of diagnostic hysteroscopy in abnormal uterine bleeding and its histopathologic correlation. J Gynecol Endosc Surg. 2009;1(2):98-104. doi:10.4103/0974-1216.71617.

18. Abdullah LS, Bondagi NS. Histopathological pattern of endometrial sampling performed for abnormal uterine bleeding. Bahrain Med Bull. 2011;33.

19. Shah R, Dayal A, Kothari S, Patel S, Dalal B. Histopathological interpretation of endometrium in abnormal uterine bleeding. Int J Med Sci Public Heal. 2014;3(4):452. doi:10.5455/ijmsph.2014.120220142.

20. Afghan S, Yasmeen A. Abnormal Uterine Bleeding (AUB) A Clinicopathological Study of 150 Cases. Ann Pak Inst Med Sci. 2013;9(4):201-204.

21. Shilpa MD. Study of Endometrial Pathology in Abnormal Uterine Bleeding. 2014;(2277):20-22.

22. Sajitha K, Shetty Kj, Hegde P, KishanPrasad H, Padma S, Permi H. Study of histopathological patterns of endometrium in abnormal uterine bleeding. CHRISMED J Heal Res. 2014;1(2):76.

23. Bhatta S, Sinha A. Histopathological study of endometrium in abnormal uterine bleeding. J Pathol Nepal. 2012;2(2277):297-300.

24. Doraiswami S, Johnson T, Rao S, Rajkumar A, Vijayaraghavan J, Panicker VK. Study of endometrial pathology in abnormal uterine bleeding. J Obstet Gynecol India. 2011;61(4):426-430.

25. Mirza T, Akram S, Mirza A, Aziz S, Mirza T, Mustansar T. Histopathological Pattern Endometrial Biopsies of Abnormal Uterine Bleeding in. 2012;(iii):114-117.

26. Damle RP, Dravid N V, Suryawanshi KH, Gadre AS, Bagale PS, Ahire N. Clinicopathological spectrum of endometrial changes in peri-menopausal and postmenopausal abnormal uterine bleeding: A 2 years study. $J$ Clin Diagnostic Res. 2013;7(12):2774-2776.

27. Anastasiadis PG, Skaphida PG, Koutlaki NG, Galazios GC, Tsikouras PN, Liberis VA. Descriptive epidemiology of endometrial hyperplasia in patients with abnormal uterine bleeding. Eur J Gynaecol Oncol. 2000;21(2):131134.

28. Noyes RW, Hertig AT, Rock J. Dating the endometrial biopsy. Am J Obstet Gynecol. 1975;122(2):262-263.

29. Bolde S, Pudale S, Pandit G, Matkari P. Histopathological study of endometrium in cases of abnormal uterine bleeding. Int J Res Med Sci. 2014;2(4):1378-1381.

30. Sandeepa S, HT J, M C A. Histopathological Study of Endometrium in Abnormal Uterine Bleeding in Different Age Groups. J Pathol Nepal. 2014;3(11):422-424.

How to cite this article: Golecha N, Porwal V. Abnormal uterine bleeding: A study of its clinical spectrum and incidence of histopathological patterns of endometrium as a function of age with parity. Ind $\mathbf{J}$ Obsted Gynecol Res. 2018;5(3):339-343. 